\title{
Effect of modified atmosphere packaging on the quality of wheat bread fortified with soy flour and oat fibre
}

\author{
Marcin Andrzej Kurek ${ }^{1}\left[\right.$ · Jarosław Wyrwisz ${ }^{1} \cdot$ Sabina Karp $^{1} \cdot$ Agnieszka Wierzbicka $^{1}$
}

Received: 11 July 2018 / Accepted: 13 March 2019 / Published online: 21 March 2019

(c) The Author(s) 2019

\begin{abstract}
Today, market searches for new alternatives to traditional food products that could be more nutritious for consumers. Modified atmosphere packaging could be used as the preservation method for the products with increased nutritional value. Therefore, the research was conducted wherein bread with added oat dietary fibre (16\% beta-glucan), and two soy flours [1.2\% (full fat soy flour (FFS)) and 14.5\% fat (defatted soy flour (DFS))] were used. The bread were stored for 3 and 7 days in normal atmosphere and with 0, 25, 50, 75 and 100\% carbon dioxide. The methodology consisted of specific volume, firmness, colour, beta-glucan and dietary fibre determination and fatty acid profile. The fatty acid profile was most promising in terms of health in the sample with added DFS (polyunsaturated fatty acids\% > 49.6). The optimisation procedure estimated that the carbon dioxide should be $15.5 \%$ for control, $38.5 \%$ for FFS, and $4.8 \%$ for DFS bread.
\end{abstract}

Keywords Dietary fibre $\cdot$ Bread $\cdot$ Optimisation $\cdot$ MAP

\section{Introduction}

Contemporary awareness of health benefits from different foods led producers to increase the functional foods supply [1]. Bread is a widely consumed staple food all over the world and provides carbohydrate, proteins, and several minerals like magnesium, iron, and phosphorus. Baked goods are considered one of the most valuable matrices for fortification with active ingredients such as dietary fibre or other bioactive components [2]. Consumers look for food not only with high quality but also with characteristics that could reduce the risk of diseases or postpone their effects [3].

Fortification of bakery products with fiber is of considerable interest of food producers as it could contribute to increased dietary fiber content in final products. Dietary fibre intake results in lowering glycemic index, reduces the risk of cancer, cardiac diseases or obesity [4]. Due to consumer acceptance, it is easier to include the dietary fibre that could be found in cereals in bakery products [5]. Oat is a very valuable cereal due to the high content of beta-glucan.

Marcin Andrzej Kurek

marcin_kurek@sggw.pl

1 Department of Technique and Food Development, Warsaw University of Life Sciences, 159C Nowoursynowska, Warsaw 02-776, Poland
The salutogenic properties of beta-glucan include lowering cholesterol level, reducing insulin production, long-lasting satiety, and decreasing blood pressure [6]. Application of dietary fibre in bread could lead to a deteriorative effect on bread quality because it alters the viscoelastic properties and the water absorption of the dough [7]. The negative impacts of additional dietary fibre in bread quality could be solved by increasing the protein content which could play a substantial role in replacing gluten.

On the other hand, there is a trend to increase the application of plant-derived protein instead of animal sources. One of such raw materials in which high amounts of protein can be found in soy flour (45-55 g/100 $\mathrm{g}$ of product). Soy has antioxidant properties that can prevent oxidative stress-induced processes and also may contribute to a longer shelf-life of the product. The inclusion of raw materials that are high in protein content like legumes or oilseed i.e. soy in the daily diet has several beneficial physiological effects in humans, including but not limited to the prevention of a range of metabolic diseases such as diabetes, coronary heart disease, and colorectal cancer [8].

Wheat is seen as a good source of protein, but taking into account the amino acid composition, it may be noted that cereals do not contain sufficient lysine content. Consequently, there are dietary programs which recommend nutritional enrichment of wheat flour with amino acids [9]. 
Adding legumes or oilseeds rich in proteins to cereal-based products is valuable from a nutritional point of view because they are rich in lysine and increase the overall protein quality in bread [10].

Optimizing bread recipes is done mainly by using statistical tools like Response Surface Methodology [11, 12]. After optimisation, the analysis of variance of predicted and measured values is the routine element that validates the recipe or shelf-life. Recent trends of bakery industry are contrary to the application of synthetic preservatives, and is more focused on the natural and neutral preservation techniques like MAP [13]. Moreover, the cost of fortified wheat bread roll is higher than regular bread and should have a longer shelf-life due to economic reasons which could be reached with the application of modified atmosphere packaging (MAP) [14]. Incorporation of dietary fibre means bread needs higher water content which could cause higher spoilage rates. Bakery products have an average water content that means moulds may be considered as the primary biological hazard. Moulds are a group of microorganisms that need oxygen to develop. In this respect, it is appropriate to use a gas mixture, where oxygen is reduced and replaced with, for example, carbon dioxide and nitrogen [15].

This study aimed to describe the effect of fortification of two different soy flours and beta-glucan as the oat dietary fiber on the quality traits of bread rolls and to optimize the best solution of MAP gas concentration for enduring shelflife employing Response Surface Methodology with developing the model which will describe the behavior of bread during MAP storage.

\section{Materials and methods}

\section{Raw materials}

Commercial wheat flour was provided by a local supplier (Polskie Młyny, Poland) and consisted of $13.72 \%$ of moisture content, $10.87 \%$ of proteins, $0.49 \%$ of ash and $27.4 \%$ of wet gluten. The composition of flour was measured with near-infrared spectroscopy (NIRFlex N-500, Buchi, Switzerland). The oat fibre powder consisted of $44 \%$ of dietary fibre (23\% of insoluble fractions, $21 \%$ of soluble fractions - with $16 \%$ of $\beta$-glucan in it) (Microstructure Inc., Poland). Soy flour was provided by Z.P.H.U ROMA and consisted of: defatted soy flour (DFS) - protein (49.8\%), water (8.92\%) and fat (1.2\%) and full-fat soy flour (FFS) - protein (53.2\%), fat $(16.5 \%)$ and water $(10.6 \%)$.

\section{Bread rolls preparation}

Constituents of bread dough included flour, $6 \%$ of pressed yeasts, $2 \%$ of salt, $1 \%$ of sugar, $1 \%$ of fat for the $100 \mathrm{~g}$ of flours or flours-beta-glucan mixture. Dietary fibre (betaglucan preparation) and soy flour replaced $20 \%$ of the flour weight with the ratio 1:1 to each other. The water content was based on the preliminary study using the rheological equipment and was assessed to be optimal with $56 \%$ for control sample, DFS - 61\% and for FFS-59\%. All constituents apart from fat were mixed with a spiral mixer with $200 \mathrm{rpm}$ for 4 min., and after adding oil, mixing was conducted for the next 6 min. (Spiral mixer TRQ—42, RM Gastro, Poland) and rested for $15 \mathrm{~min}$. Then, the dough was divided into $60 \mathrm{~g}$ rolls and formed. The proofing time was $50 \mathrm{~min}$. for each one with $37{ }^{\circ} \mathrm{C}$ and $80 \% \mathrm{RH}$. Bread rolls were baked at $180{ }^{\circ} \mathrm{C}$ for $14 \mathrm{~min}$. in a convection oven (Convection oven CPE 110, Kuppersbuch, Germany).

\section{Bread rolls packaging}

After cooling for $3 \mathrm{~h}$ at ambient temperature, the bread rolls were packed into transparent polypropylene bags (PP package, thickness $550 \mu \mathrm{m}$ ) and cover PET/CPP/AF laminate (thickness $44 \mu \mathrm{m}$ ). Each bread rolls group was packed at $105 \mathrm{kPa}$ pressure and supplied with an initial gas mixture: $0,25,50,75$ and $100 \% \mathrm{CO}_{2}$ and nitrogen as inert gas using a packing machine (Sealpac M3, Oldenburg, Germany), then stored in darkness at ambient temperature.

\section{Physical measurements}

\section{Specific volume and moisture}

The specific volume was measured using seed displacement method and calculated as $\mathrm{cm}^{3} / \mathrm{g}$ of bread rolls. Moisture was measured as the percentage of water that evaporated after overnight drying at $105^{\circ} \mathrm{C}$.

\section{Texture analysis}

Mechanical characteristics of bread in a double compression cycle were recorded in a Universal Testing Machine Instron 5965 (Instron, USA) with the maximal load of 500N, $50 \%$ penetration depth using a $40-\mathrm{mm}$ diameter probe and a 20-s gap between compressions on the crumb cubes of $20 \times 20 \times 20 \mathrm{~mm}$. The results were given as maximum level of firmness $[\mathrm{N}]$ and springiness of five samples from each batch of recipe and packaging [14].

\section{Porosity}

The porosity was estimated using image computer analysis. The loaf was cut into slices with the thickness of $2.5 \mathrm{~cm}$. The photograph of the slice was taken using a digital camera (QImagining, Micro Publisher 5.0 RTV) with lighting from lamps (Osram Dulux L 36W/954, day-light) with the colour 
temperature $5400 \mathrm{~K}$. Images were saved as TIFF format. Then they were analysed by the program ImagePro. The image was converted into an 8-bit image to obtain a black and white threshold, and then the binary segmentation was done. The results were presented as a percentage of pore area in total.

\section{Microscopy}

The microstructure of bread was assessed using light and fluorescence microscope. The pieces of breadcrumb were fixed in $10 \%$ formalin, then dehydrated in ascending concentrations of ethanol and put in xylene prior to embedding in paraffin. Then, the block was formed, and sections with $10 \mu \mathrm{m}$ were immobilised on a slide. After drying, they were stained in $0.1 \%$ of light green dye for light microscopy. The $0.1 \%$ of acid fuchsin in $1 \%$ of acetic acid and $0.01 \%$ of calcofluor for fluorescence microscopy (Fluorescent brightener 28, Aldrich, Germany). Calcofluor stains beta-glucan blue. Fuchsin acid stains proteins are red. Starch remains unstained and appears black.

\section{Colour}

Colour determinations were carried out on breadcrumb and using a Minolta CR-400 colourimeter (Konica Minolta Inc., Japan) (illuminant D65, measurement area $\varnothing=8 \mathrm{~mm}$, standard observers $2^{\circ}$ ), and the results were expressed in accordance with the CIELab colour space. Determined parameter was lightness $-\mathrm{L}^{*}(\mathrm{~L}=0$ (black) and $\mathrm{L}=100$ (white)). There were taken shots by the colourimeter ten times at the crumb and crust from three different rolls [16].

\section{Overall quality}

Bread quality evaluation was performed by organoleptic assessment tests through hedonic score system from 1 (the lowest note) to 9 (the highest note) as the overall acceptance as consumers. Panellists were selected from post-graduate students and teaching members of the Department of Technique and Food Development. The test were performed in day 1,4 and 7 of storage.

\section{Chemical measurements}

\section{Total dietary fibre, $\beta$-glucan and raffinose content}

The total dietary fibre (TDF) in baked bread rolls was measured according to the AOAC 2009.01 method using the FOSS Fibretec E 1023 system (FOSS Inc., USA) and Megazyme TDF Assay Kit. The total $\beta$-glucan content and raffinose content was determined using the Megazyme Inc. beta-glucan mixed linkage kit and raffinose/D-galactose assay kit, respectively (MegaZyme Inc., Ireland) [16].

\section{Protein and fat content}

Protein content was measured by the Kjeldahl method with 6.25 factor used for determination of protein from nitrogen content. Total fat was estimated by modified Folch extraction during preparation before esterification of fatty acids.

\section{Fatty acids profile}

Fatty acids profile was assessed basing on the esterification of fat. $10 \mathrm{~g}$ of grounded bread were homogenised with a mixture of petroleum ether and acetone $(1: 1, \mathrm{v} / \mathrm{v})$ for $2 \mathrm{~min}$ at $12 \mathrm{k} \mathrm{rpm}$. Then, the slurry was filtered to a glass separator, and the $20 \%$ of $\mathrm{NaCl}$ solution was added to divide the phases. The upper phase was transferred to a roundbottomed flask and evaporated to dryness. Then the fat residue was solved in hexane. To $2 \mathrm{ml}$ of hexane $2 \mathrm{ml}$ of $1 \mathrm{M} \mathrm{KOH}$ in methanol was added and put in a water bath for $10 \mathrm{~min}$ in $55^{\circ} \mathrm{C}$. After phases separation the sample was cleaned with $2 \mathrm{ml}$ of distilled water, $1 \mathrm{ml}$ of $20 \% \mathrm{NaCl}$ and $2 \mathrm{ml}$ of hexane. The upper phase was transferred to an autosampler vial, and the chromatographic analysis was performed with GC-2010 chromatograph. The column was Restek $100 \mathrm{~m} \times 0.25 \mathrm{~mm} \times 0.2 \mu \mathrm{m}$, and the temperature program was $100{ }^{\circ} \mathrm{C}(5 \mathrm{~min})$ to $240{ }^{\circ} \mathrm{C}(30 \mathrm{~min})$ at $4{ }^{\circ} \mathrm{C} /$ min, detector: FID $260{ }^{\circ} \mathrm{C}$ with injection volume: $1 \mu$ l. The fatty acids esters content was calculated comparing to Supelco 37 FAME Component Mix (Sigma Aldrich, Germany).

\section{Statistics}

The combinations of concentrations of carbon dioxide $\left(\mathrm{CO}_{2}\right)$ and days (D) of storage were considered as the independent variables, using central composite design with three entry variables with one centre point, two blocks which led to the 11 runs of experiments. The minimum levels of gas concentration were $0 \%$ and the maximum $100 \%$. There were two variables for days of storage-day 1 and day 7 . The coefficients of the polynomial were represented as intercept value, linear, interaction and quadratic term. Obtained data were analysed using Design Expert 9. version 9 (Stat-Ease, Inc.). The significant terms of this model were found by the analysis of variance (ANOVA) for each response, the lack of fit, and coefficients of determination $\left(\mathrm{R}^{2}\right)$, which were calculated to check the model accuracy. The models fitted in this study were utilised for optimisation purposes using the desirability function. This process consists of converting 
each response variable into a desirability function di from 0 to 1 . It is necessary to find the factor levels that correlate with a maximum response variable value so that $d=1$ for high values and $d=0$ for low values of response variable should be set [2].

\section{Results and discussion}

\section{Checking of the models}

Response surface data analysis was performed to examine the results of the experiment. The statistical significance of the obtained models was checked with ANOVA. Each of the models observed was not significant regarding the lack of fit and most of the $\mathrm{R}^{2}$ coefficient obtained values higher than 0.85 what validated the adequacy of models. The models were statistically adequate and were used for studying the influence of the type of packaging and day of storage on 17 responses.

\section{Specific volume and moisture content}

The regression analysis of the variables in quadratic terms are presented in Table 1. The control sample had the lowest values of specific volume during the experiment (intercept 3.01, while for FFS and DFS 3.28 and 3.31). The $\mathrm{CO}_{2}$ played a significant role $(\mathrm{p} \leq 0.001)$ in decreasing the volume of rolls in CON and FFS. However, the quadratic term of the day of storage was significant in affecting the volume of CON sample $(p \leq 0.001)$. The FFS and DFS bread had a higher amount of protein and the beta-glucan addition. The mechanism that was observed here was discovered in glutenfree formulations with HPMC as hydrocolloid [17]. Betaglucan had similar hydrocolloidal properties and stabilised the walls of pores in bread [18]. Moreover, soy protein is an excellent emulsifier and stabilises the structure better [3].

The moisture content was significantly higher in the samples with FFS and DFS which was affected by the higher water content in mixing step to obtain sufficient consistency of dough. The $\mathrm{CO}_{2}$ in packaging atmosphere and interaction factor between the $\mathrm{CO}_{2}$ and day of storage significantly influenced $(\mathrm{p} \leq 0.05)$ the moisture. However, the sample with FFS tended to hold the moisture in $\mathrm{CO}_{2}$ packaging, while the moisture values in DFS had a reverse direction. Moisture content was moreover affected by the addition of beta-glucan due to its high water-holding properties [18]. The effect of carbon dioxide in MAP was observed as well in other food matrices when the moisture decreased during storage due to the migration of water into other parts of the packaging [19]. Moreover, this could be explained by the fact that $\mathrm{CO}_{2}$

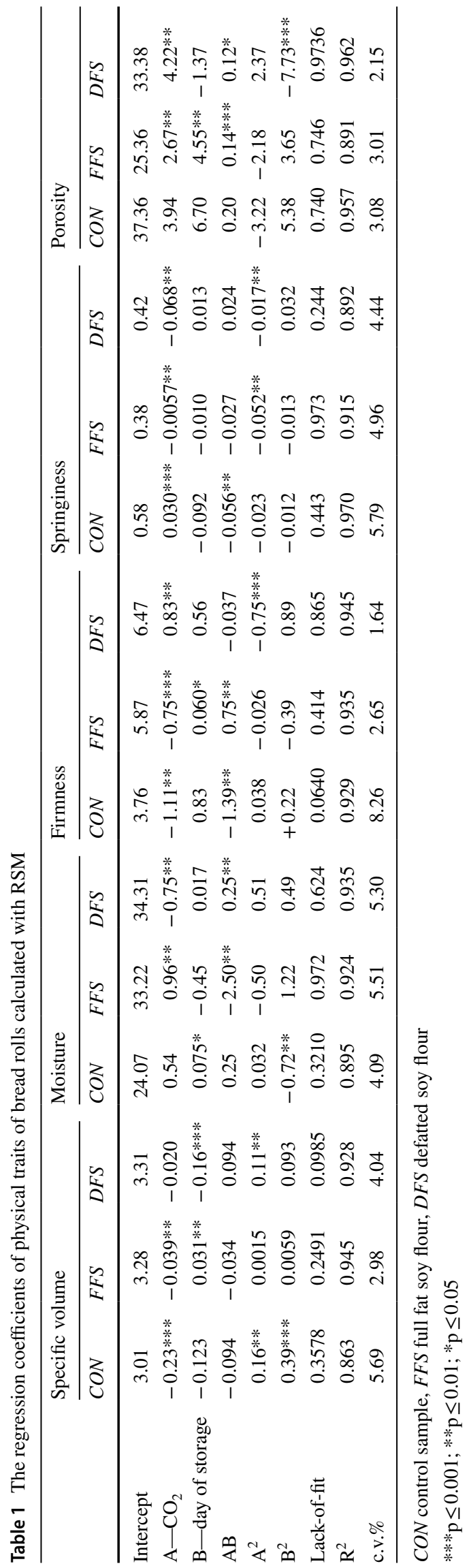


has high diffusivity into the product which cause changes of microstructure of bread and distribution of water molecules in the whole product volume [20].

\section{Textural parameters and porosity}

The textural parameters that were examined in the experiment were firmness and springiness (Table 1). The lowest values of firmness were observed in CON sample $(3.76 \mathrm{~N})$ while the highest in DFS- $6.47 \mathrm{~N} . \mathrm{CO}_{2}$ influenced the firmness negatively in CON and FFS samples due to the fact that $\mathrm{CO}_{2}$ delays staling of bread when used as the atmosphere. Probably this is connected to the fact that during storage amylopectin still remained the component with water binding ability. $\mathrm{CO}_{2}$ blocks these bonds and cause the reduction of hydrogen bonding between amylopectin branches which are mainly responsible for staling [21]. The obtained results were similar to those observed by Shin et al. [17] where the specific volume of bread with soy flour negatively correlated with firmness. In CON sample the interaction between the $\mathrm{CO}_{2}$ and day of storage showed a negative impact on firmness with the tendency to lower this parameter $(\mathrm{p} \leq 0.05)$. Springiness is the parameter which is measured to find out in what share the texture of the bread is resistant to force. In conducted experiment similarly to firmness, $\mathrm{CO}_{2}$ was the significant factor for all samples $(\mathrm{p} \leq 0.01)$. The highest values were observed in control sample, and the $\mathrm{CO}_{2}$ does not influence it negatively, but the springiness of FFS decreased at the highest pace. Bread with soy flour is known for having higher firmness due to dilution of gluten matrix which could be more visible because of beta-glucan addition. Moreover, the interchange of disulphide bonds between soy and gluten proteins, and absorption of water by soy fibre causing an increase in dough viscosity could be here a factor as well Shin et al. [21]. The results that were observed in our study led to the statement that the gas composition of MAP could influence the texture attributes of bread with soy and betaglucan what is contrary to Khoshakhlagh et al. [22].

The values of porosity were at least in the FFS sample, while the highest was in $\mathrm{CON}$. The $\mathrm{CO}_{2}$ played a significant role in enlarging this parameter $(\mathrm{p} \leq 0.05)$. The porous structure of all bread rolls on day 1 and day 7 are presented in Fig. 1. The fact that carbon dioxide influenced the porosity could be influenced by the migration of gases between the interior of bread rolls and the atmosphere packaging. Because $\mathrm{CO}_{2}$ is mainly responsible for the formation of pore the presence of it in packaging could be a vital factor as well which is consistent to the results obtain by previous research performed by Morren et al. [20] who proved that diffusivity of gases used as the atmosphere in MAP play important role in developing the microstructure of bread [23].

\section{Microstructure of bread wheat rolls}

The micrographs of bread rolls are presented in Fig. 2. It is visible in the light microscopy images that the FFS and DFS samples had smaller pores and the structure of bread was formed more regularly in FFS samples due to fat that could influence better stabilisation could be observed even though it was disrupted by beta-glucan and gluten-free flour.
Fig. 1 Porosity of bread roll crumb on day 1 and day 7 stored in 0 and $100 \%$ of carbon dioxide. CON control sample, $F F S$ full fat soy flour, $D F S$ defatted soy flour

\section{$0 \% \mathrm{CO}_{2}$}

Day 1

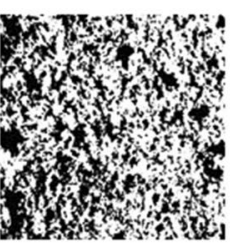

FFS

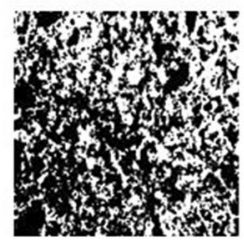

DFS

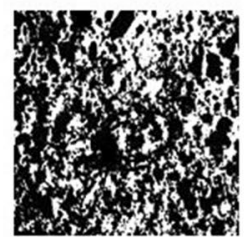

Day 7
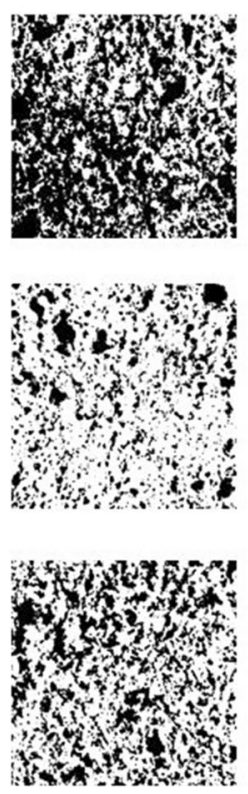

$100 \% \mathrm{CO}_{2}$
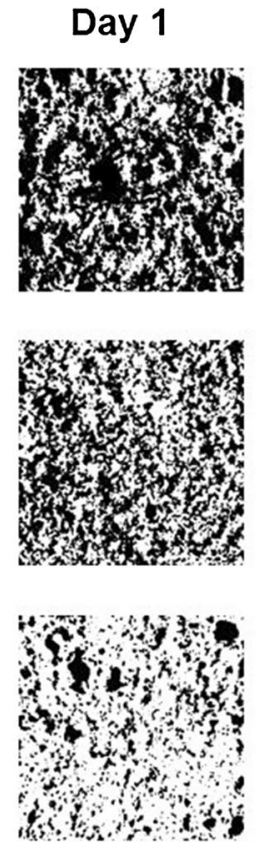

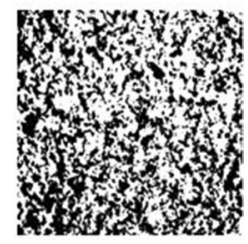

Day 7
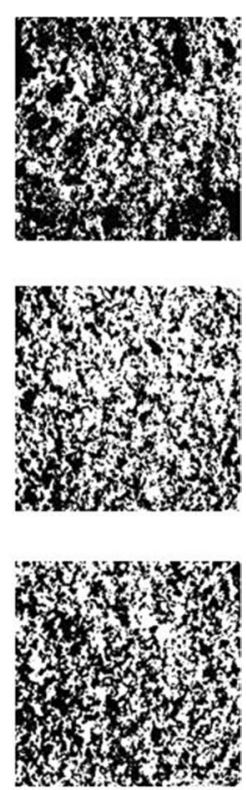


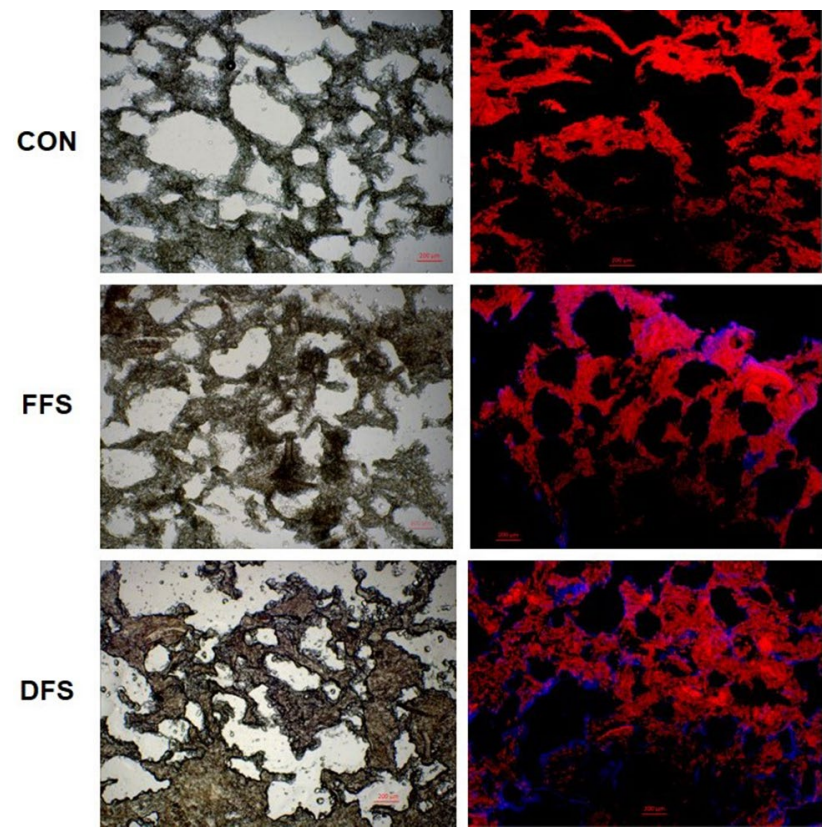

Fig. 2 Microstructure of bread roll crumb in light and fluorescence microscopy. CON control sample, FFS full fat soy flour, DFS defatted soy flour

The fluorescence microscopy revealed that beta-glucan was more regularly distributed in the whole structure in DFS samples than in the FFS (blue color on the photographs). It could be explained by the higher fat content in FFS which could form an emulsion with beta-glucan in the dough as the visosifier, and the chemical structure of beta-glucan could not associate calcofluor as a strainer. The more red colour appeared in the samples with FFS and DFS due to the higher protein content. In control sample only gluten proteins were stained with red dye [24].

\section{Lightness}

The lightness was measured as the most important value in assessing the quality of bread by the consumers. The highest $\mathrm{L}^{*}$ value of the crumb was observed in control sample while the $\mathrm{CO}_{2}$ influenced significantly only the DFS sample in this parameter (Table 2). The highest $\mathrm{L}^{*}$ of the crust was observed as well while only $\mathrm{CO}_{2}$ was only a significant factor in quadratic terms. Crust color is an important attribute of bread, contributing to consumer preference. It is produced by chemical reactions including Maillard reaction and caramelisation [25]. The incorporation of soy flour and beta-glucan modified the crust colour of the bread, but the effect of $\mathrm{CO}_{2}$ was not significant, but it could be employed in the model.

\section{Overall quality}

The overall quality was assessed on the nine-point hedonic scale with 30 consumers. Contrary to preliminary hypothesis, the highest values were observed in DFS sample. The day of storage significantly influences the decrease of quality in CON and DFS samples $(\mathrm{p} \leq 0.001)$. The similar tendency regarding sensory liking could be observed in the study performed by Padhi et al. [26] where the soy flour was added as the functional ingredient to muffins. Up to $20 \%$ addition of soy flour replacement of wheat flour did not change the taste or the aroma of the bread [27,28], so this could be a reason for a significant change of overall quality of bread rolls. Moreover, the addition of beta-glucan could lead to a decrease in overall quality [2], but it was not observed in our study. The $\mathrm{CO}_{2}$ concentration did not change the overall quality significantly which is desirable observation due to the usage of carbon dioxide to prolong the freshness of bread [29].

Table 2 The regression coefficients of L* (lightness) and overall quality of bread rolls calculated with RSM

\begin{tabular}{|c|c|c|c|c|c|c|c|c|c|}
\hline & \multicolumn{3}{|l|}{$\mathrm{L}^{*}$ crumb } & \multicolumn{3}{|l|}{$\mathrm{L}^{*}$ crust } & \multicolumn{3}{|c|}{ Overall quality } \\
\hline & $C O N$ & $F F S$ & $D F S$ & $C O N$ & $F F S$ & $D F S$ & $C O N$ & $F F S$ & $D F S$ \\
\hline Intercept & 74.38 & 70.19 & 69.83 & 42.85 & 40.33 & 40.30 & 5.93 & 6.11 & 6.96 \\
\hline $\mathrm{A}-\mathrm{CO}_{2}$ & 0.26 & -0.084 & $0.061 * * *$ & 0.21 & -0.035 & -0.017 & -0.052 & 0.18 & $0.080^{*}$ \\
\hline B-day of storage & -0.46 & -0.47 & 0.19 & -0.26 & -0.32 & 0.11 & $-1.12 * * *$ & $0.17 *$ & $-1.73 * * *$ \\
\hline $\mathrm{AB}$ & -0.13 & 0.018 & -0.56 & 0.038 & 0.012 & $-0.31 * *$ & 0.22 & $-0.76^{* *}$ & 0.064 \\
\hline $\mathrm{A}^{2}$ & $0.64 * *$ & $-0.90 * *$ & $0.70 * *$ & $0.39 * *$ & $-0.51 * *$ & $0.31 *$ & $0.34 * *$ & 0.29 & -0.12 \\
\hline $\mathrm{B}^{2}$ & -0.29 & $0.96 * *$ & 0.29 & -0.27 & $+0.59 * *$ & 0.034 & 0.37 & 0.22 & $-0.22 * *$ \\
\hline Lack-of-fit & 0.220 & 0.9314 & 0.917 & 0.2712 & 0.6684 & $0 . .889$ & 5.93 & 0.544 & 0.5294 \\
\hline $\mathrm{R}^{2}$ & 0.856 & 0.897 & 0.889 & 0.845 & 0.823 & 0.824 & 0.794 & 0.842 & 0.963 \\
\hline c.v. $\%$ & 1.37 & 1.40 & 1.49 & 1.52 & 1.38 & 1.61 & 8.42 & 1.78 & 1.45 \\
\hline
\end{tabular}

CON control sample, FFS full fat soy flour, DFS defatted soy flour

$* *{ }^{*} \leq 0.001 ; * \mathrm{p} \leq 0.01 ; * \mathrm{p} \leq 0.05$ 
Table 3 The regression coefficients fat and fatty acids analysis of bread rolls calculated with RSM

\begin{tabular}{|c|c|c|c|c|c|c|c|c|c|c|c|c|}
\hline & \multicolumn{3}{|l|}{ Fat } & \multicolumn{3}{|l|}{ SFA } & \multicolumn{3}{|l|}{ PUFA } & \multicolumn{3}{|l|}{ MUFA } \\
\hline & $C O N$ & $F F S$ & $D F S$ & $C O N$ & $F F S$ & $D F S$ & $C O N$ & $F F S$ & $D F S$ & $C O N$ & $F F S$ & $D F S$ \\
\hline Intercept & 3.03 & 4.45 & 3.63 & 0.60 & $3.63 * *$ & 0.67 & 41.37 & 41.48 & 49.56 & 60.32 & 49.13 & 41.54 \\
\hline $\mathrm{A}-\mathrm{CO}_{2}$ & $-0.14 *$ & 0.012 & 0.058 & $0.055^{* *}$ & $-0.046^{*}$ & 0.025 & $0.58 * * *$ & $0.010 * *$ & $0.11 * *$ & -0.47 & -0.17 & 0.028 \\
\hline $\mathrm{B}$ - day of storage & -0.081 & $-0.37 * *$ & -0.051 & $-0.028^{*}$ & $0.013 * *$ & -0.009 & 0.22 & -0.12 & 0.14 & -0.28 & $0.24 * *$ & -0.18 \\
\hline $\mathrm{AB}$ & $0.16^{* *}$ & $-0.20 * * *$ & 0.15 & 0.035 & -0.054 & $-0.14 * *$ & $-0.23 * *$ & $-0.84 * * *$ & 0.21 & 0.19 & $0.38 * *$ & $0.36^{*}$ \\
\hline $\mathrm{A}^{2}$ & -0.10 & -0.072 & 0.082 & 0.012 & -0.045 & +0.056 & 0.090 & 0.24 & -0.14 & 0.12 & 0.033 & -0.21 \\
\hline $\mathrm{B}^{2}$ & -0.046 & -0.038 & 0.037 & 0.026 & 0.022 & $-0.069 * * *$ & 0.11 & -0.019 & -0.14 & 0.32 & 0.026 & 0.0084 \\
\hline Lack-of-fit & 0.535 & 0.646 & 0.339 & 0.187 & 0.962 & 0.705 & 0.519 & 0.488 & 0.308 & 0.620 & 0.664 & 0.665 \\
\hline $\mathrm{R}^{2}$ & 0.829 & 0.876 & 0.934 & 0.878 & 0.804 & 0.798 & 0.889 & 0.951 & 0.834 & 0.896 & 0.926 & 0.719 \\
\hline c.v. $\%$ & 1.44 & 1.30 & 1.34 & 2.89 & 1.42 & 1.42 & 1.25 & 1.97 & 1.10 & 2.03 & 0.83 & 1.47 \\
\hline
\end{tabular}

CON control sample, FFS full fat soy flour, DFS defatted soy flour

$* * * \mathrm{p} \leq 0.001 ; * * \mathrm{p} \leq 0.01 ; * \mathrm{p} \leq 0.05$

Table 4 The regression coefficients from determination of raffinose, beta-glucan, dietary fiber an protein content in bread rolls calculated with RSM

\begin{tabular}{|c|c|c|c|c|c|c|c|c|c|c|}
\hline & \multicolumn{2}{|c|}{ Raffinose } & \multicolumn{2}{|c|}{ Beta-glucan } & \multicolumn{3}{|c|}{ Dietary fiber } & \multicolumn{3}{|l|}{ Protein } \\
\hline & $F F S$ & $D F S$ & $F F S$ & $D F S$ & $C O N$ & $F F S$ & $D F S$ & $C O N$ & $F F S$ & $D F S$ \\
\hline Intercept & 62.55 & 57.26 & $+1.42 * *$ & 1.49 & 2.06 & 6.06 & +6.52 & 8.40 & 11.28 & 11.07 \\
\hline $\mathrm{A}-\mathrm{CO}_{2}$ & 0.71 & 0.42 & -0.026 & -0.0078 & $-0.007 *$ & $-0.028 * *$ & $+0.19 * * *$ & 0.030 & -0.18 & 0.15 \\
\hline B-day of storage & 0.40 & -0.48 & -0.0057 & 0.0035 & 0.026 & $0.048 * * *$ & -0.067 & -0.055 & -0.075 & -0.041 \\
\hline $\mathrm{AB}$ & -0.26 & -0.16 & -0.0037 & 0.0035 & 0.0093 & -0.0098 & $-0.20 * *$ & -0.049 & 0.38 & 0.39 \\
\hline $\mathrm{A}^{2}$ & -0.18 & $-0.76^{* *}$ & -0.0378 & $0.016^{* *}$ & -0.017 & $-0.028 * *$ & -0.003 & 0.11 & 0.011 & -0.063 \\
\hline $\mathrm{B}^{2}$ & -0.35 & $-0.93 * * *$ & -0.0047 & $0.018 * * *$ & 0.00794 & 0.0048 & -0.063 & 0.13 & -0.13 & -0.15 \\
\hline Lack-of-fit & 0.454 & 0.459 & 0.615 & 0.998 & 0.555 & 0.547 & 0.2193 & 0.127 & 0.874 & 0.368 \\
\hline $\mathrm{R}^{2}$ & 0.803 & 0.789 & 0.879 & 0.851 & 0.844 & 0.789 & 0.968 & 0.862 & 0.889 & 0.848 \\
\hline c.v. $\%$ & 2.51 & 1.15 & 1.97 & 1.73 & 1.94 & 0.56 & 1.89 & 3.72 & 1.52 & 1.65 \\
\hline
\end{tabular}

CON control sample, FFS full fat soy flour, DFS defatted soy flour

$* * * \mathrm{p} \leq 0.001 ; * * \mathrm{p} \leq 0.01 ; * \mathrm{p} \leq 0.05$

\section{Chemical properties}

The fat, protein, and dietary fibre content were examined to determine the basic components present in the bread rolls and are presented in Tables 3 and 4 . The highest fat content was observed in FFS due to adding FFS. The day of storage influenced the fat content in all samples negatively. The protein content was significantly higher in the samples with soy flour $(>11.0 \mathrm{~g} / 100 \mathrm{~g})$. This situation is influenced by adding the soy flour which was high in protein. The content of protein was not influenced by any measured parameters. Dietary fibre content was highest $(>6.06 \mathrm{~g} / 100 \mathrm{~g})$ in bread rolls with added soy and dietary fibre.

The products that are based on soy should have the reduced quantity of raffinose [28]. Raffinose is the polysaccharide that is present in pulses, so generally, its content is measured in research using soy as well. The content of raffinose was similar in FFS and DFS (from 58 to
$62 \mathrm{mg} / 100 \mathrm{~g}$ ). Only the quadratic terms of $\mathrm{CO}_{2}$ and day of storage decreased its content significantly $(\mathrm{p} \leq 0.01$ and $\mathrm{p} \leq 0.05$ ). The results obtained in the study were consistent with the results obtained from measuring raffinose content in soy flour [29]. The mechanism that affects the soy content in bread rolls is heating which leads to heat hydrolysis of oligosaccharides to disaccharides and monosaccharides [28].

The fatty acid profile was examined and presented as regression coefficients in Table 3. Only FFS sample had significantly higher values of SFA (3.63\%). The $\mathrm{CO}_{2}$ significantly increased the SFA in CON sample $(\mathrm{p} \leq 0.05)$. PUFA content was highest in DFS sample (49.56\%), while the $\mathrm{CON}$ and FFS had similar values. $\mathrm{CO}_{2}$ significantly increased the content of PUFA in all measures samples $(p \leq 0.01)$. Contrary, the MUFA content was highest in CON sample (60.32\%). Only the day of storage significantly increases the MUFA content in FFS sample $(\mathrm{p} \leq 0.05)$. The fatty acid profile in soy-enriched bread was more beneficial 
Table 5 Values of selected measured optimized parameters in comparison to predicted from the models

\begin{tabular}{|c|c|c|c|c|c|c|c|c|c|c|}
\hline & \multicolumn{2}{|c|}{ Specific volume $\left(\mathrm{cm}^{3} / \mathrm{g}\right)$} & \multicolumn{2}{|c|}{ Firmness (N) } & \multicolumn{2}{|c|}{ Springiness $(\mathrm{N})$} & \multicolumn{2}{|c|}{ Porosity (\%) } & \multicolumn{2}{|c|}{ Overall quality } \\
\hline & Predicted & Measured & Predicted & Measured & Predicted & Measured & Predicted & Measured & Predicted & Measured \\
\hline $\mathrm{CON}$ & 3.23 & 3.25 & 3.07 & 3.10 & 0.627 & 0.621 & 50.33 & 49.98 & 5.97 & 5.87 \\
\hline FFS & 3.52 & 3.58 & 3.53 & 3.59 & 0.565 & 0.572 & 42.15 & 41.95 & 6.36 & 6.74 \\
\hline DFS & 3.18 & 3.09 & 3.13 & 3.09 & 0.415 & 0.425 & 35.08 & 34.09 & 6.19 & 6.27 \\
\hline
\end{tabular}

CON control sample, FFS full fat soy flour, DFS defatted soy flour

for human health [30]. The beta-glucan content was only identifiable in the samples FFS and DFS due to the addition of beta-glucan preparation. The intercept values were higher than 1.42 , so the product could obtain the health statement as blood cholesterol decreasing factor [31].

\section{Optimization and verification of the model}

The optimisation study aimed to develop the optimal $\mathrm{CO}_{2}$ concentration to obtain the best possible quality performance. The optimisation was done setting firmness and raffinose (in FFS and DFS) as minimum desirable value and as the most valuable function maximum length of storage, specific volume, springiness, porosity and overall quality with dietary fibre content higher than $6.0 \mathrm{~g} / 100 \mathrm{~g}$ of product. The optimised $\mathrm{CO}_{2}$ concentration was calculated as $15.5 \%$ for CON, 38.5\% for FFS and 4.8\% for DFS. The verification of model was done and the measured and predicted values after 3 days of storage are presented in Table 5. There were no significant differences observed between the measured and predicted samples.

\section{Conclusions}

Optimization of the $\mathrm{CO}_{2}$ content in the packaging of a control sample, FFS, and DFS, and effects of day of storage and $\mathrm{CO}_{2}$ concentration on quality traits of bread rolls was performed using response surface methodology. Regression analysis was done for modelling of variables to obtain the optimal conditions of storage with maintaining highest possible quality. It could be concluded that the addition of beta-glucan and soy flour increase the specific volume, moistureand firmness of bread rolls. The addition of soy flour and beta-glucan could be valuable fortification strategy to obtain the bread rolls with healthy properties due to the high content of dietary fibre and PUFA. The optimal $\mathrm{CO}_{2}$ concentrations in MAP could be valuable information for commercial storage of enriched bread rolls.

Open Access This article is distributed under the terms of the Creative Commons Attribution 4.0 International License (http://creativeco mmons.org/licenses/by/4.0/), which permits unrestricted use, distribution, and reproduction in any medium, provided you give appropriate credit to the original author(s) and the source, provide a link to the Creative Commons license, and indicate if changes were made.

\section{References}

1. I. Siró, E. Kápolna, B. Kápolna, A. Lugasi, Appetite 51, 456-467 (2008)

2. D. Mudgil, S. Barak, B. Khatkar, J. Cereal Sci. 70, 186-191 (2016)

3. S.K. Chakraborty, S. Gupta, N. Kotwaliwale, J. Food Sci. Technol. 53, 4308-4315 (2016)

4. N.C. Øverby, E. Sonestedt, D.E. Laaksonen, B.E. Birgisdottir, Food Nutr. Res. 57, 207-209 (2013)

5. A.M. Jalil, C.A. Edwards, E. Combet, M. Ibrahim, A.L. Garcia, Int. J. Food Sci. Nutr. 66, 159-165 (2015)

6. F. Ronda, S. Perez-Quirce, A. Lazaridou, C.G. Biliaderis, Food Hydrocoll. 48, 197-207 (2015)

7. C.M. Mancebo, C. Merino, M.M. Martínez, M. Gómez, J. Food Sci. Technol. 52, 6323-6333 (2015)

8. F. Guillon, M.J. Champ, Br. J. Nutr. 88, 293-306 (2002)

9. C.A. Patterson, H. Maskus, C.M.C. Bassett, Cereal Food World 55, 56-62 (2010)

10. M. Erben, C.A. Osella, Food Sci. Technol. Int. 23, 457-468 (2017)

11. P. Kittisuban, P. Ritthiruangdej, M. Suphantharika, LWT-Food Sci. Technol. 57, 738-748 (2014)

12. N. O’Shea, C. Rößle, E. Arendt, E. Gallagher, Food Chem. 166, 223-230 (2015)

13. A.T. Passarinho, N.F. Dias, G.P. Camilloto, R.S. Cruz, C.G. Otoni, A.R. Moraes, N.D. Soares, J. Food Process Eng. 37, 53-62 (2014)

14. J. Wyrwisz, M. Kurek, S. Karp, M. Moczkowska, A. Stelmasiak, A. Wierzbicka, J. Food Process Eng. (2017). https://doi. org/10.1111/jfpe. 12494

15. M. Fik, K. Surówka, I. Maciejaszek, M. Macura, M. Michalczyk, J. Cereal Sci. 56, 418-424 (2012)

16. M.A. Kurek, J. Wyrwisz, A. Wierzbicka, LWT-Food Sci. Technol. 57, 738-748 (2017)

17. D.J. Shin, W. Kim, Y. Kim, Food Chem. 141, 517-523 (2013)

18. M.A. Kurek, J. Wyrwisz, A. Wierzbicka, CyTA-J. Food 14, 124 130 (2016)

19. C. Costa, A. Lucera, V. Lacivita, M.A. Saccotelli, A. Conte, M.A. Del Nobile, Int. J. Dairy Technol. 69, 401-409 (2016)

20. S. Morren, Q. Tri Ho, J. Stoops, T. Dyck, J. Claes, P. Verboven, B. Nicolaï, Food Bioprocess Technol. 10, 328-339 (2017)

21. L. Nilufer-Erdil, D. Serventi, Y. Boyacioglu, Vodovotz, Food Chem. 131, 1132-1139 (2012)

22. K. Khoshakhlagh, N. Hamdami, M. Shahedi, A. Le-Bail, J Food Eng. 140, 52-59 (2014) 
23. Y. Avital, C.H. Mannheim, J. Miltz, J. Food Sci. 55, 413-416 (1990)

24. M. de la P. Salgado-Cruz, M. Ramírez-Miranda, M. Díaz-Ramírez, L. Alamilla-Beltran, G. Calderón-Domínguez, Food Hydrocoll. 69, 141-149 (2017)

25. P.D. Ribotta, G.T. Pérez, M.C. Añón, A.E. León, Food Bioprocess Technol. 3, 395-405 (2010)

26. E.M. Padhi, D.D. Ramdath, S.J. Carson, A. Hawke, H.J. Blewett, T.M. Wolever, A.M. Duncan, Food Res. Int. 77, 491-497 (2015)

27. B. Ivanovski, K. Seetharaman, L.M. Duizer, J. Food Sci. 77, 71-76 (2012)

28. N. Singh, A.M. Kayastha, J. Plant Biochem. Biotechnol. 22, 353356 (2013)

29. K. Khoshakhlagh, N. Hamdami, M. Shahedi, A. Le-Bail, J. Cereal Sci. 60, 42-47 (2014)
30. M. Taghdir, S.M. Mazloomi, N. Honar, M. Sepandi, M. Ashourpour, M. Salehi, Food Sci. Nutr. 5, 439-445 (2017)

31. EFSA Panel on Dietetic Products, Nutrition and Allergies (NDA). Scientific Opinion on the, substantiation of a health claim related to oat beta glucan and lowering blood cholesterol and reduced risk of (coronary) heart disease pursuant to Article 14 of Regulation (EC) No 1924/2006. EFSA J. (2010). https://doi.org/10.2903/j. efsa.2010.1885

Publisher's Note Springer Nature remains neutral with regard to jurisdictional claims in published maps and institutional affiliations. 